Lepr Rev (1994) 65, 167-174

\title{
Indeterminate leprosy: a seroimmunological and histochemical evaluation
}

\author{
B. SEKAR, R. N. SHARMA*, D. ANANDAN, \\ B. VASANTHI \& M. JAYASHEELA \\ Laboratory Division \& Clinical Division*, Central Leprosy Teach- \\ ing and Research Institute, Chengalpattu-603001, Tamil Nadu, \\ S. India
}

Accepted for publication 7 February 1994

\begin{abstract}
Summary An effort was made to differentiate indeterminate (IND) leprosy from other types of the paucibacillary (PB) group of leprosy and to identify among indeterminate leprosy cases those which may evolve to multibacillary (MB) leprosy, using serological, immunological and histochemical parameters. A total of 92 untreated, histologically classified (TT-19, BT-30, IND-32) patients, including 11 cases diagnosed as nonspecific dermatitis (NSD), which were clinically strongly suspected to be leprotic, were screened for antibodies against PGL-I, 35-kDa and LAM antigens. Lepromin tests and antigen demonstration in tissue by indirect immunoperoxidase staining were also carried out. Though a qualitative analysis did not differentiate, a quantitative analysis in terms of a cumulative index (CI) showed a higher antibody level amongst the indeterminate group of patients than the other groups included in PB leprosy. Also, the lepromin negative indeterminate group patients showed a higher CI than the lepromin positive cases, indicating that perhaps these may be the cases which may develop into MB leprosy. Thus, the semiquantification of antibody levels in the form of a CI may be a useful parameter to predict the possible evolution of a given case of indeterminate leprosy. Interestingly $64 \%$ of NSD cases had either antigen or antibody which indicated that they were probably cases of leprosy.
\end{abstract}

\section{Introduction}

Indeterminate leprosy, a clinical entity, diagnosed in conjunction with histological and bacteriological investigations, is an early and unstable form of leprosy. Its histopathological picture is that of a simple, nonspecific inflammation involving the nerve with or without acid-fast bacilli (AFB) in the nerve or in the subepidermal zone or in the arrectores pilorum muscles. The lesions of indeterminate leprosy may undergo spontaneous healing or remain unchanged for many years. They may also change to one of the more stable types of clinical leprosy, ${ }^{1}$ which can be histologically confirmed by demonstrating either epithelioid cell granuloma or macrophage ganuloma loaded with 
bacilli. ${ }^{2}$ Though classified under the paucibacillary (PB) group of leprosy for the purpose of managment, indeterminate leprosy (IND), thus, can potentially downgrade into the multibacillary (MB) group of leprosy. Efforts to identify parameters which can predict the evolution of a case of indeterminate leprosy have been made earlier and certain clinical, immunological and histopathological parameters have been identified. ${ }^{3-8}$

In the present study, we have attempted to differentiate cases of indeterminate leprosy from other types of PB leprosy, and to identify amongst them the ones which may develop into MB leprosy, using serological, immunological and histochemical parameters.

\section{Materials and methods}

A total of 92 untreated cases of clinically diagnosed leprosy attending the Central Leprosy Teaching and Research Institute (CLT \& RI) outpatient department were included in the study. Histopathologically, they were tuberculoid (TT-19), borderlinetuberculoid (BT-30) and indeterminate (IND-32) types. In addition, there were 11 cases which were histopathologically diagnosed as nonspecific dermatitis (NSD) but were strongly suspected to be clinical cases of leprosy and were included in the study.

Sera from all the patients were collected and stored at $-20^{\circ} \mathrm{C}$ for antibody assays. Sections from skin biopsy of the lesions stained by haematoxylin and eosin and FiteFaraco methods were examined. Histochemical studies were carried out by immunoperoxidase staining of the tissue sections. A routine slit-skin smear examination from 6 sites, such as both earlobes, extensor aspect of arms and thighs, including representative active skin lesions, was made to assess the bacteriological index (BI).

\section{Antibody assays}

All the sera were screened for antiphenolicglycolipid-I (anti PGL-I), antilipoarabinomannan (anti-LAM) and anti-35 kDa antibodies.

\section{ANTIPGL-I ASSAY}

IgM antiPGL-I antibodies were measured by using the procedure reported earlier. ${ }^{9}$ Briefly, D-BSA supplied by IMMLEP-WHO, was coated in duplicate in a 96-well flat bottom microtitre plate (Dynatec Micro-ELISA System, Germany). Sera (1:300 diluted) were added to both antigen and BSA coated wells. After incubation antihuman IgM peroxidase conjugate (DAKOPATTS, Denmark) was added ( $1: 2000$ diluted), colour was developed with o-phenylenediamine (SIGMA, USA) with $\mathrm{H}_{2} \mathrm{O}_{2}$. Reaction was stopped with $5 \mathrm{NH}_{2} \mathrm{SO}_{4}$. The plates were read at $492 \mathrm{~nm}$ in an ELISA reader. Samples with a difference in the mean absorbance between the antigen and BSA coated wells equal to or more than 0.200 OD were considered positive.

SERUM ANTIBODY COMPETITION TEST-ELISA (SACT-E)

Antibody to the Mycobacterium leprae specific $35 \mathrm{kDa}$ protein was detected as reported 
earlier. ${ }^{10}$ Briefly, M. leprae soluble extract $10 \mu \mathrm{g} / \mathrm{ml}$ (kindly supplied by R. J. W. Rees, IMMLEP $M$. lepra Bank) in PBS was coated in a microtitre plate (Immulon, M129 B Dynatec). Sera in 10-fold dilutions of $1: 10,1: 100$ and $1: 1000$ were added in duplicate and incubated for $1 \mathrm{hr}$. After removing sera, appropriately diluted peroxidase conjugated ML-04 monoclonal antibody (kindly supplied by J. Ivanyi, MRC, the Royal Postgraduate Medical School, London) was added and incubated for $2 \mathrm{hr}$. After washing, colour was developed with o-phenylenediamine substrate solution. The reaction was stopped with $5 \mathrm{NH}_{2} \mathrm{SO}_{4}$ and a reading was taken at $492 \mathrm{~nm}$ in an ELISA reader. The dilution of the sera causing 50\% inhibition of binding of ML-04 to the antigen $\left(\mathrm{ID}_{50}\right)$ was calculated. Samples with $\mathrm{ID}_{50}$ titres equal to or more than 10 were considered to be SACT-E positive.

\section{ANTILAM ELISA}

IgG antiLAM antibodies were measured as reported earlier. ${ }^{10}$ Briefly LAM from $M$. tuberculosis H37Ra (kindly supplied by D. Chatterjee, Colorado State University, Fort Collins, Colorada, USA) was coated at $1 \mu \mathrm{g} / \mathrm{ml}$. Control wells were coated with buffer. Sera (1:1000 diluted) were added to all the wells. After incubation antihuman IgG (1: 6000 diluted) was added, then o-phenylenediamine and $\mathrm{H}_{2} \mathrm{O}_{2}$ were added as a substrate solution. The reaction was stopped and plates were read at $492 \mathrm{~nm}$. Samples with a difference in the mean absorbance between the antigen and control wells equal to or more than $0 \cdot 500 \mathrm{OD}$ were considered positive.

\section{Antigen detection}

Antigen detection in the sections from paraffin blocks was done by indirect immunoperoxidase staining.

\section{RAISING OF ANTIMLSE ANTIBODY}

Rabbits were immunized with $M$. leprae soluble extract (MLSE), using a standard protocol. $^{11}$ The serum immunoglobulins were concentrated by ammonium sulphate precipitation and followed by extensive dialysis. This polyvalent antibody was used as primary antibody in immunoperoxidase staining.

\section{IMMUNOPEROXIDASE STAINING}

Indirect immunoperoxidase staining was done using a standard procedure. ${ }^{12}$ Briefly, after deparaffinization and quenching with $\mathrm{H}_{2} \mathrm{O}_{2}$, the slides were blocked with $1: 10$ diluted normal swine serum. After incubation for $10 \mathrm{~min}$, primary antibody (antiMLSE, $1: 200$ diluted) was added to the sections. After a further 1-h incubation, antirabbit IgG peroxidase conjugate (DAKOPATTS, Denmark; 1:100 diluted) was added. After washing with PBS, diaminobenzidine containing $0.02 \% \mathrm{H}_{2} \mathrm{O}_{2}$ was used for colour development. After washing in water, the slides were counterstained with Harris haematoxylin, dried and mounted in DPX. Microscopially antigen appeared as a brown precipitate, within or outside the granuloma. Normal rabbit serum as primary antibody was used in controls. 


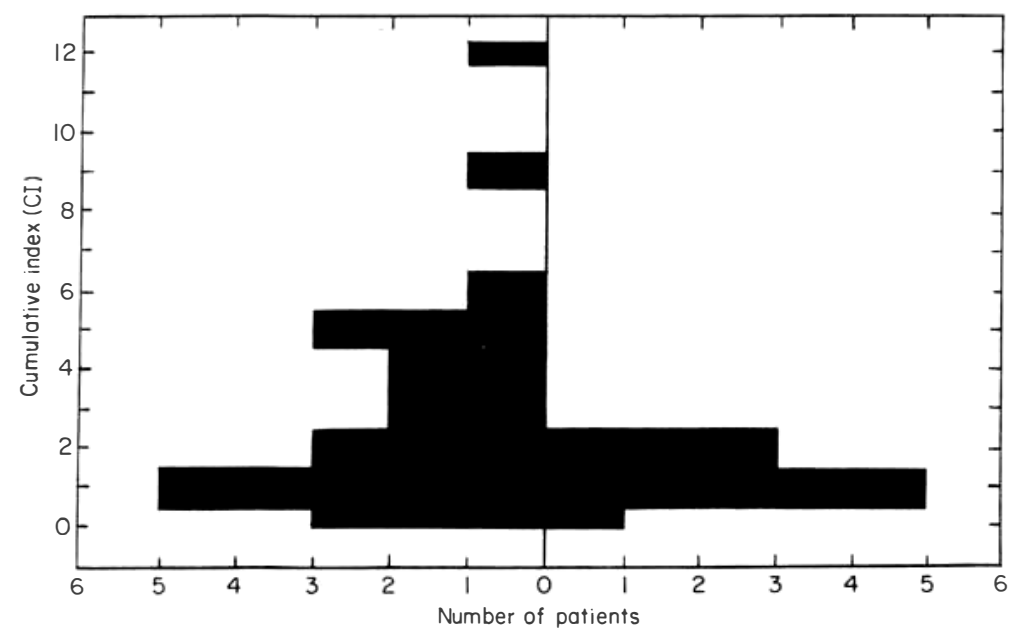

Figure 1. Histogram showing the distribution of cumulative index (CI) amongst lepromin negative (left side) and lepromin positive (right side) cases of indeterminate leprosy.

\section{Lepromin test}

Lepromin testing was done using Mitsuda lepromin (kindly supplied by M. J. Colston, MRC, National Institute for Medical Research, London). Early and late readings were taken after $48 \mathrm{hr}$ and 21 days, respectively.

\section{Statistical analysis}

All descriptive and statistical analyses were carried out using SPSS/PC + and EPI-INFO software packages. The statistical significance between different groups was detected using the Chi-squared test, and Fischer's exact test was used where the expected value was less than 5. The significance of the cumulative index (CI) was determined by using Student $t$-two tailed tests. The probability value of $<0.05$ was considered to be significant. The data represented in Figure 1 are composed of rectangles with numbers of patients and CI.

\section{Result}

ANTIBODY ASSAY (TABLE 1)

Analysis of positivity for individual antibodies (namely, antiPGL, antiLAM and anti35 $\mathrm{kDa})$ showed that there was a significant difference between IND and TT only $(p<0.05$; for antiLAM, $p$ value could not be calculated for antiPGL and anti35 kDA since no case of TT was positive for both the antibodies) and not between IND and BT or NSD $(p>0.05)$. The analysis of positivity for any of three antibodies (namely antiPGL/antiLAM/anti35 $\mathrm{kDa}$ ) also revealed a significant difference only between IND and TT $(p<0.05)$ and not between IND and others $(p>0.05)$. 
Table 1. Serological, immunological and histochemical parameters in indeterminate and other groups of patients

\begin{tabular}{|c|c|c|c|c|}
\hline \multirow[b]{2}{*}{ Groups } & \multicolumn{4}{|c|}{ Number of patients $(\%)$} \\
\hline & IND & TT & BT & NSD \\
\hline No. of cases & 32 & 19 & 30 & 11 \\
\hline Positive for antiPGL antibody & $10(31)$ & 0 & $5(17) \mathrm{NS}$ & 2 (18) NS \\
\hline Positive for anti $35 \mathrm{kDa}$ antibody & $7(22)$ & 0 & 1 (3) NS & $2(18) \mathrm{NS}$ \\
\hline Positive for antiLAM antibody & $13(41)$ & $2(11) \mathrm{S}$ & 6 (20) NS & $4(36) \mathrm{NS}$ \\
\hline Positive for any of three antibodies & $17(53)$ & $2(11) \mathrm{S}$ & $9(30) \mathrm{NS}$ & $5(46) \mathrm{NS}$ \\
\hline Positive for antigen & $20(63)$ & $6(32) \mathrm{NS}$ & $20(67) \mathrm{NS}$ & 5 (46) NS \\
\hline $\begin{array}{l}\text { Positive for any of three } \\
\text { antibodies/antigen }\end{array}$ & $26(81)$ & $8(42) \mathrm{S}$ & $24(80) \mathrm{NS}$ & 7 (64) NS \\
\hline $\begin{array}{l}\text { Cumulative index of three } \\
\text { antibodies (mean } \pm \text { SD) }\end{array}$ & $\begin{array}{r}1 \cdot 812 \\
\pm 2 \cdot 62\end{array}$ & $\begin{array}{l}0.315 \\
\pm 0.79 \mathrm{~S}\end{array}$ & $\begin{array}{l}0.733 \\
\pm 1.28 \mathrm{~S}\end{array}$ & $\begin{array}{l}1 \cdot 36 \\
\pm 1 \cdot 8 \mathrm{NS}\end{array}$ \\
\hline Lepromin negative ( $<4 \mathrm{~mm}$ ) & $\frac{21}{30}(70)$ & $\frac{2}{14}(14) \mathrm{S}$ & $\frac{6}{25}(24) \mathrm{S}$ & $\frac{6}{09}(67) \mathrm{NS}$ \\
\hline
\end{tabular}

The significance of difference was observed between the referred group and indeterminate group. NS, not significant $(p>0.05)$; Significant $(p<0.05)$; SD, standard deviation.

\section{ANTIGEN DETECTION (TABLE 1)}

There was no significant difference in the positivity for antigen by immunoperoxidase staining amongst the different groups (IND-63\%, TT - 32\%, BT-67\%, NSD-46\%) $(p>0 \cdot 05)$.

\section{ANTIBODY WITH ANTIGEN (TABLE 1)}

When positivity for any of the 3 antibodies and for antigen was analysed, a significant difference was observed only between IND and TT groups $(p<0 \cdot 05)$, but not between IND and other groups $(p>0 \cdot 05)$.

\section{LEPROMIN TEST (TABLE 1)}

Lepromin negativity was observed significantly more amongst the IND group than the TT and BT groups $(p<0 \cdot 05)$. But there was no difference between IND and NSD groups $(p>0.05)$.

\section{CUMULATIVE INDEX (TABLE 1)}

An attempt was made to semiquantify the antibody levels by grading the OD/titre of the 3 antibodies. The absence of the antibody was graded 0 . The different antibodies when present were graded as follows, considering the cut-off, frequency and highest OD/titre recorded for each antibody and as far as possible with equal class interval: antiPGL-I antibody, grade $1=0.200$ to 0.400 , grade $2=>0.400$ to 0.600 , grade $3=>0.600$ to $0 \cdot 800$, grade $4=>0 \cdot 800$ to $1 \cdot 00$; antiLAM antibody, grade $1=0.500$ to $0 \cdot 700$, grade $2=>0 \cdot 700$ to 0.900 , grade $3=>0.900$ to $1 \cdot 10$, grade $4=>1 \cdot 1$ to $1 \cdot 3$; anti35 $\mathrm{kDa}$ antibody, grade $1=10$ to 100 , grade $2=>100$ to 500 , grade $3=>500$ to 1000 , grade $4=>1000$. The grades of different antibodies of an individual patient were cumulated 
Table 2. Analysis of different parameters between lepromin positive and lepromin negative groups of indeterminate leprosy

\begin{tabular}{lcc}
\hline & \multicolumn{2}{c}{ Number of patients (\%) } \\
\hline $\begin{array}{l}\text { Groups } \\
\text { No. of cases }\end{array}$ & Lepromin positive & Lepromin negative \\
$\begin{array}{l}\text { Positive for antiPGL antibody } \\
\text { Positive for anti35 kDa antibody }\end{array}$ & $9(30)$ & $21(70)$ \\
$\begin{array}{l}\text { Positive for antiLAM antibody } \\
\text { Positive for any of three antibodies }\end{array}$ & $1(11)$ & $9(43) \mathrm{NS}$ \\
$\begin{array}{l}\text { Positive for antigen } \\
\text { Positive for any of } \\
\text { three antibodies/antigen }\end{array}$ & $2(22)$ & $6(29) \mathrm{NS}$ \\
$\begin{array}{l}\text { Cumulative index of } \\
\text { three antibodies } \\
\text { (mean } \pm \text { SD) }\end{array}$ & $7(78)$ & $11(52) \mathrm{NS}$ \\
& $8(87) \mathrm{NS}$ \\
& & $13(62) \mathrm{NS}$ \\
\end{tabular}

NS, not significant $(p>0.05)$; S, significant $(p<0.05)$.

and referred to as $\mathrm{CI}$ for the given patient. Analysis of CI amongst the different groups revealed that cases in the IND group had significantly higher CI than cases in the other groups of PB leprosy $(p<0 \cdot 05)$. Thus, though no significant difference was observed in terms of positivity for different antibodies individually or in combination between the IND and other groups (except TT), a significant difference was observed in terms of quantification - antibody levels being higher in the IND cases.

In the light of these findings, further analysis was made to find the difference, if any, between lepromin positive and lepromin negative groups of cases of IND leprosy. Amongst IND leprosy, 21 cases $(70 \%)$ were lepromin negative and 9 cases $(30 \%)$ were lepromin positive (Table 2). Analysis of the positivity for individual antibodies or combination of antibodies and also the positivity for antigen did not reveal any significant difference between lepromin positive and negative groups $(p>0.05)$, whereas, analysis of CI revealed a highly significant difference between the lepromin positive and negative groups $(p<0.05)$, being higher in the lepromin negative group (Figure 1).

\section{Discussion}

It is well known that indeterminate leprosy is an unstable clinical entity, which can progress either to the tuberculoid or lepromatous form. Few studies have attempted to search for some clinical, immunological and histopathological parameters which can predict the probable course of a case of indeterminate leprosy. ${ }^{3-8}$ Studies on serological responses of leprosy patients to $M$. leprae specific (PGL, $35 \mathrm{kDa}$ ) and mycobacteria specific (LAM) antigens have shown uniformly higher responses in the MB group of patients than in the PB groups. ${ }^{13-15}$ Amongst the PB group an apparently higher response to these antigen was observed in the indeterminate group. ${ }^{10}$ Using these antibody assays as well as antigen detection by the immunoperoxidase staining method, an attempt was made to differentiate the indeterminate type from other 
forms of the PB group and to identify amongst the indeterminate group those who may develop into the LL form of leprosy.

The number of patients serologically responding to different antigens was comparable in all groups except in the TT group where significantly fewer responded. It has already been shown that the sensitivity of these individual antibody assays is too low to be of practical value and it is possible to increase the sensitivity without loss of specificity by using these assays in combinations. ${ }^{10}$ Even such an analysis in this study showed a comparable increase in the sensitivity for all groups except in the TT group which was again significantly lower than the IND group. Antigen by immunoperoxidase staining was demonstrable in comparable numbers of cases in different groups including the TT group. The CI, which quantifies the antibody levels, revealed that the indeterminate group of patients had significantly higher antibody levels than other groups when qualitative analysis did not differentiate the indeterminate group from others. A positive Mitsuda skin reaction amongst the indeterminate group is known to indicate the probable evolution of the case towards the TT pole $\mathrm{e}^{3,4}$ and similarly a negative reaction towards the LL pole of leprosy. ${ }^{7}$ In our study, a significantly higher number of indeterminate patients was found to be negative to lepromin. In both lepromin positive and negative patients of this group, the results of different antibody assays, both individually and in combination were comparable, and antigen was demonstrable equally in both the groups. But quantification in terms of CI showed significantly higher antibody levels amongst the lepromin negative group.

Earlier studies have shown that the lepromin negative indeterminate group can potentially progress to LL. ${ }^{7}$ Flies et al. ${ }^{6}$ identified certain CMI parameters, which when altered denoted downgrading of a lepromin negative indeterminate case towards the LL pole. ${ }^{6}$ A marked dermal nerve involvement in conjunction with bacteriological and immunohistochemical markers of low resistance to infection were indicative of a probable early downgrading of the disease and these parameters could be semiquantified into an $\Sigma 3$ index, where an $\Sigma 3$ index $=>6$ detected cases evolving to MB leprosy. ${ }^{8}$ Our study identified higher antibody levels in terms of CI amongst indeterminate than other PB groups. Amongst the indeterminate group lepromin negative cases had higher CI. This may be the group which will downgrade to the LL form of leprosy. Further study on these lines may be more enlightening.

In our study, antigen was demonstrable equally in all the groups though all of them were PB leprosy and were negative for AFB both in skin smear and in tissue sections. This observation emphasizes the higher sensitivity of the immunoperoxidase staining method in demonstrating the presence of pathogen in the lesions. ${ }^{8}$

We histopathologically diagnosed as nonspecific dermatitis 11 of the cases included in the study, which had been strongly clinically suspected of leprosy. However, $64 \%$ of this group had any of three antibodies or the antigen by immunoperoxidase staining which was comparable with the indeterminate group. Even the quantification of antibody was comparable with that of indeterminate leprosy. Hence it may be stated that though they are NSD by histopathological examination, perhaps they are leprosy cases. A search for the antigen in the tissue or for the antibody in sera amongst histopathologically diagnosed NSDs, may be a useful supplement to the clinical diagnosis. Further indepth study is required to confirm this observation. These are the cases, which are probably indeterminate leprosy, but may be histologically too indefinite to be branded so. Thus when indeterminate leprosy is diagnosed and found to be 
lepromin negative with higher antibody levels, close follow up will be necessary during treatment and surveillance, as these cases may subsequently develop MB leprosy. The semiquantification of antibody levels in terms of the cumulative index (CI) would be a usef ul parameter to predict the evolution of a given case of indeterminate leprosy.

\section{Acknowledgments}

We thank IMMLEP/WHO for the supply of D-BSA antigen; Dr R. J. W. Rees for the provision of $M$. leprae soluble extract through IMMLEP/WHO/UNDP/World Bank Tropical Disease Research Programme; Professor J. Ivanyi for providing ML-04 conjugate; Dr D. Chatterjee for supplying LAM antigen; and Dr M. J. Colston for supplying Mitsuda lepromin. Our sincere thanks are given to Mr L. Rathinavel, Mr G. Yusuff, Mr K. Kuberan, Mr S. Elumalai and Mrs G. Saraswathi, Laboratory Division of CLT\&RI, for their dedicated technical assistance. We thank Dr V. D. Ramanathan, TRC, Chetput for his help in immunoperoxidase staining; Mr M. Subramanian and Dr P. Krisnamoorthy, Epidemiology and Statistical Division, CLT\&RI for their assistance in statistical analysis; and Dr P. S. Rao, Director-in-Charge, CLT\&RI for all his encouragement. The help of Mr K. S. Sethurman, Photography Section, CLT\&RI in the preparation of the histogram is also acknowledged.

\section{References}

1 Dharmendra. Leprosy. Kothari Medical Publishing House, 1978; vol I: 46.

2 Ridley DS. Indeterminate Leprosy (Editorial). Lepr Rev, 1974; 45: 95-7.

3 Bungeler W. Die pathologische Anatomie der lepra. Virchow Arch (A), 1943; 310: 493-565.

${ }^{4}$ Roteberg A. Valor prognostico da lepromino reacao de Mitsuda: observacao de 445 casos durante 5-6 anos. Rev Bras Leprol, 1944; 12: 367-77.

5 Bechelli LM. Indeterminate leprosy in a population survey and in the subsequent follow-ups of children in Burma. Acta Leprol, 1989; 7(1): 29-36.

${ }^{6}$ Flies EL, Bachman AE, Sasiain M del C, Ares BR. Immunological studies in patients with Indeterminate Leprosy. Rev Asos Argent Microbiol, 1975; 7(3): 81-5.

7 Alchrome MMA, Rotberg A, Michalany J, Vargas P De O, Cassiano TP. Prognostic consideration based on a study of 38 hanseniasis patients submitted to Mitsuda tests 23 to 35 years previously. Hansenologia Internacionalis, 1978; 3: 5-11.

8 Takahashi MD, Andrade Jr HF, Wakamatsu A, Siqueira S and De Brito T. Indeterminate Leprosy: Histopathologic and histochemical predictive parameters involved in it's possible change to paucibacillary or multibacillary leprosy. Int J Lepr, 1991; 59: 12-19.

9 Dhandayuthapani S, Anandan D, Vasanthi B, Bhatia VN. Use of eluates of filter paper blood spots in ELISA for the serodiagnosis of leprosy. Indian J Med Res, 1989; 89: 150-7.

10 Sekar B, Sharma RN, Leelabai G, Anandan D, Vasanthi B, Yusuff G, Subramanian M, Jayasheela M. Serological response of leprosy patients to Mycobacterium leprae specific and mycobacteria specific antigens: possibility of using these assays in combinations. Le pr Rev, 1993; 64: 15-24.

11 Harboe M, Closs O, Bjorvatn B, Kronvall G, Axelsen NH. Antibody response in rabbits to immunization with Mycobacterium leprae. Inf Immun, 1977; 18: 792-805.

12 Mshana RN, Belehu A, Stoner GL, Harboe M, Haregewoin A. Demonstration of Mycobacterial antigens in leprosy tissues. Int J Lepr, 1982; 50: 1-10.

13 Bach MA, Wallach D, Flageul B, Haffenbach A, Conttenot F. Antibodies to phenolic glycolipid-I and to whole Mycobacterium leprae in leprosy patients; evolution during therapy. Int J Le pr, 1986; 54: $256-67$.

14 Mwatha J, Moreno C, Sengupta U, Sinha S, Ivanyi J. A comparative evaluation of serological assays for lepromatous leprosy. Lepr Rev, 1988; 59: 195-9.

15 Chanteau S, Cartel JL, Celerier P, Plichart R, Desforges S, Roux J. PGL-I antigen and antibody detection in leprosy patients: Evolution under chemotherapy. Int J Lepr, 1989; 57: 735-43. 